\title{
Ontological turns in contemporary political science: in search for compliance with politics
}

\section{V. Smorgunov ${ }^{1}$}

\begin{tabular}{lr}
\hline 1St. Petersburg State University, 7/9 Universitetskaya Emb., Saint Petersburg 199034, Russian Federation \\
\hline DOI: $10.18255 / 2412-6519-2020-2-122-133$ & Research Article \\
Full text in Russian
\end{tabular}

The article reveals the content of the main trends in the development of contemporary political science in connection with crisis phenomena affecting its thematic, methodological and theoretical problems, as well as its connection with real political practice. The logic of the search for new political thinking consists in a sequential transition from solving the problems of the crisis in the field of interdisciplinary methodological synthesis to considering the unity of political methodology and ontology, and then to ontologizing political studies expressed in two ontological turns. Interdisciplinary synthesis involves overcoming the boundaries between qualitative and quantitative research, as well as the natural and social sciences. The unity of political methodology and ontology was based on the recognition of the primacy of substantive political research. The first ontological turn concerned criticism of the post-political review of politics and attempts to substantiate political theory and philosophy as a fact of politics. In the thematic plan, attention was paid to disclosing the content of the political and substantiating the relationship between philosophy and politics. The second ontological turn led to the politicization of ontology and the ontologization of politics by criticizing metaphysics, rationalism, and human subjectivity. This turn is expressed in the new political realism, which includes actor-network theory and object-oriented ontology.

Keywords: political science, crisis, interdisciplinary synthesis, unity of methodology and ontology, ontological turn, the political, political reality, politicization of ontology, ontologization of politics

INFORMATION ABOUT THE AUTHORS

\begin{tabular}{l|l} 
Smorgunov Leonid V. & $\begin{array}{l}\text { E-mail: l.smorgunov@spbu.ru } \\
\text { Doctor of Sciences in Philosophy, Professor, head } \\
\text { of the Department of Political Governance }\end{array}$
\end{tabular}

Funding: Russian Science Foundation, grant 19-18-00210 "Political ontology of digitalization: Study of institutional bases for digital forms of governability".

For citation: Smorgunov L. V. Ontological turns in contemporary political science: in search for compliance with politics // Social'nye i gumanitarnye znanija. 2020. Vol. 6, No 2. P. 122-133. (in Russ.)

(C) Smorgunov L. V., 2020

This is an open access article under the CC BY-NC-ND license (http://creativecommons.org/licenses/by-nc-nd/4.0/) 


\title{
Онтологические повороты в современной политической науке: в поисках адекватности политике
}

\author{
Л. В. Сморгунов ${ }^{1}$
}

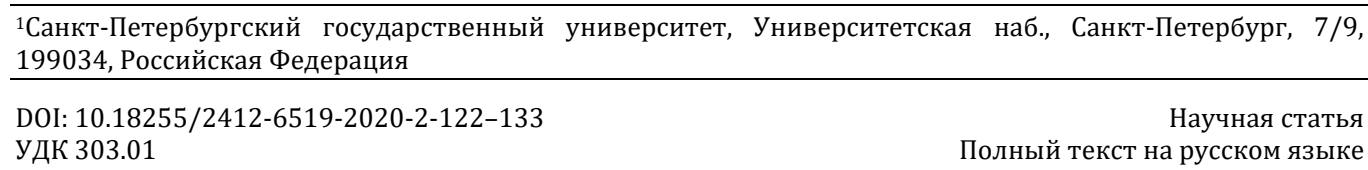

В статье раскрывается содержание основных тенденций в развитии современной политической науки в связи с кризисными явлениями, затрагивающими ее тематические, методологические и теоретические проблемы, а также ее связи с реальной политической практикой. Логика поиска нового политического мышления состоит в последовательном переходе от решения проблем кризиса в области междисциплинарного методологического синтеза к рассмотрению единства политической методологии и онтологии, а затем к онтологизации политических исследований, выраженных в двух онтологических поворотах. Междисциплинарный синтез связан с преодолением границ, разделяющих качественные и количественные исследования, а также естественные и общественные науки. Единство политической методологии и онтологии опиралось на признание первенства исследования политической субстанции. Первый онтологический поворот касался критики постполитического рассмотрения политики и попытки обоснования политической теории и философии как факта политики. В тематическом плане здесь внимание уделялось раскрытию содержания политического (the political) и обоснованию соотношения философии и политики. Второй онтологический поворот привел к политизации онтологии и онтологизации политики путем критики метафизики, рационализма и человеческой субъектности. Данный поворот выражается в новом политическом реализме, включающем в себя акторно-сетевую теорию и объектно-ориентированную онтологию.

Ключевые слова: политическая наука, кризис, междисциплинарный синтез, единство методологии и онтологии, онтологический поворот, политическое, политическая реальность, политизация онтологии, онтологизация политики

ИНФОРМАЦИЯ ОБ АВТОРАХ

Сморгунов Леонид Владимирович

E-mail: l.smorgunov@spbu.ru

Доктор философских наук, профессор, заведующий

кафедрой политического управления

Финансирование: РНФ, грант 19-18-00210 «Политическая онтология цифровизации: исследование институциональных оснований цифровых форматов государственной управляемости».

Для цитирования: Сморгунов Л. В. Онтологические повороты в современной политической науке: в поисках адекватности политике // Социальные и гуманитарные знания. 2020. Том 6, № 2. С. $122-133$. 


\section{Введение}

Тема поиска нового мышления в политическом знании имеет много векторов рассмотрения. Древнегреческое понимание этого вопроса связано с поиском различий между политическим мышлением политика и философа (ученого) (Сократ, Платон, Аристотель, Ксенофонт). Девятнадцатый век в связи с дифференциацией наук сформулировал конфликт между номотетическим и идеографическим знанием (зафиксированным в истории общественной науки в виде длящегося конфликта двух традиций - дюркгеймовской и веберовской). Двадцатый век обострил тему соотношения интеллектуального (способность знать) и философского (способность думать) мышления в политике (Л. Штраус, А. Кожев, Х. Арендт). Постмодернизм поставил под сомнение тотальное и универсальное знание (деконструкция, плюрализм, различие/спор (le differance), поверхность), а постструктурализм связал это знание с властью и сформулировал потребность освобождения знания от властных интенций. Политическая наука/философия ответила постмодернизму широким движением неоинституционализма, обеспечившего институциональный порядок в политике на основе прежде всего рационального выбора. Однако неоинституционализм и рациональный выбор столкнулись с новыми реалиями цифрового общества, когда устойчивый порядок политики и политического знания стал подвергаться эрозии неопределенности, хаоса, постправды и опасности иррационализма. Движения в области наук о науке и технологии обострили вопрос о действенности технических средств в пространствах взаимодействия человека и природы. Технологии, особенно цифрового характера, стали рассматриваться не просто как инструменты, посредствующие человеческое влияние на природу. Цифровая политика в отличие от политики цифровизации приобрела характер фактора, трансформирующего социум и природу.

Все эти процессы заставили пересматривать условия и механизмы взаимодействия человеческих и нечеловеческих актантов преобразований. В политической науке стали проявляться тенденции, которые отражали усложнение политической реальности в эпоху четвертой промышленной революции. Хотя в мировом и российском пространстве политической науки многое было сделано и делается для решения возникших проблем, однако следует согласиться с тем, что «в настоящее время ощущается исчерпанность инерционного движения, но выйти за его пределы пока не удается» [1, с. 37].

В данной статье обращается внимание на некоторые тенденции последнего времени в политической науке, которые свидетельствуют об интенсивных поисках новых подходов и решений относительно знания и реальной политики. Здесь будет обращено внимание на попытку междисциплинарного синтеза, поиск единства методологического и онтологического подходов, а также на два онтологических поворота в политическом познании.

\section{Попытка междисциплинарного синтеза}

На стыке последних столетий в политической науке и в политическом познании вообще, если включать в него политическую философию и смежные дисциплины, явно обозначилась тенденция междисциплинарного совмещения научных интересов в виде сложного мышления и междисциплинарного синтеза естественнонаучных и социолого-политологических методов. Последние версии сциентистского 
анализа (теория хаоса, синергетика, квантовая механика, фрактальная теория) представляют собой самостоятельные подходы при изучении сложных (адаптивных) систем, которые не подчиняются линейному развитию, включают в себя синергетические компоненты самоорганизации, бифуркационные потоки, нелинейные причинные зависимости, квантовые неопределенности, сложные фрактальные размерности и т. д. Сложность, как считается, является результатом самой реальности, т. е. принадлежит к объекту исследования.

Изучение сложных систем в традициях сциентизма, начавшееся в физике, биологии и компьютерных науках, начинает проникать и в область общественных наук. Особое место эта проблема занимает в политической науке [2; 3] и в изучении публичной политики [4; 5]. В этом отношении предсказуемым было то применение теории сложности в социальных науках, включая исследование политики, которое фокусировалось на нелинейности, нестабильности и неопределенности: «Политическая сфера является определенно нелинейной, где нестабильность и непредсказуемость являются внутренними и где причина и следствие часто загадочно смешиваются. Очевидный факт, что политические системы являются историческими и временными системами, также повышает потенциальную ценность в применении теории сложности в социальных науках» [6, р. 132].

Однако исследование сложности в политике не означает выбор только синергетической парадигмы. Значительное влияние на изучение сложности оказывает так называемый культурный уклон в социальных науках, который предполагает рассматривать сложность, исходя из феноменологического характера нашего восприятия действительности, т. е. ориентироваться не на объективность, а на беспристрастность исследователя. Феномен сложного мышления является составной частью феномена сложного мира. Его основной императив состоит в способности нашего мышления сопоставлять друг с другом различные стратегии человеческого мышления и действия и находить адекватные решения, соотносимые с ситуацией и контекстом. В этом отношении сложное мышление веротерпимо и плюралистично, т. е. допускает и однолинейные стратегии, которые должны встроиться в сложную картину формирующейся реальности, не нарушая, а дополняя синергетический эффект. Сложность и неустойчивый характер современного общественного мира порождают феномены, которые трудно объяснить в рамках прежних теоретических парадигм. Вот почему нарастает движение за новый взгляд на общество и новую теоретическую парадигму. В методологическом отношении пробивают дорогу синтетические подходы, такие как квантовая политика, теория сложных сетей, фрактальная теория [7]. В теоретическом отношении одной из новых парадигм описания сложности выступает концепция лиминальности. Если теория сложных систем, сложных сетей, фрактальная геометрия относится к сциентистской парадигме сложности, то теория лиминальности, проистекающая из антропологии и постколониальных исследований, а также формирующееся событийное знание относятся к философско-культурологическому направлению.

\section{Единство методологического и онтологического подходов}

Все предыдущие подходы в политической науке опирались на первенство методологии в получении объективного, обоснованного, детерминистского знания о политической реальности. В начале XXI в. вектор анализа смещается в сторону единства онтологического и методологического подходов. В этом отношении повы- 
шается значение качественных методов исследования, а также стремление к объединению качественных и количественных подходов. Отличие этой дискуссии от предыдущих данное поколение разработчиков новых подходов (Махони, Беннет, Эльман, Мунк) связывает с инновационной постановкой ряда вопросов и утверждением значимости качественных методов. Важным в современной дискуссии о качественной методологии является вопрос не только о том, как исследовать, но и о том, какова природа исследуемой реальности. Приоритет субстанциальных ориентаций над количественными соотношениями приводит к возрождению интереса к политической онтологии, что вызывает так называемый «онтологический поворот» в политическом знании. На первый план изучения политической реальности выходит единство онтологии и методологии, а значит, погружение науки в реальность, превращение знания о политике в факт политической действительности.

Если применительно к 1990-м гг. Герардо Мунк отмечал тенденцию к качественной методологии в политическом исследовании как одиночные попытки найти синтетическую основу для различных подходов [8], то уже в 2007 г. он вместе с Ричардом Снайдером писал относительно доминирующей отрасли в политической науке сравнительной политологии, что «относительно объекта, предмета и методов сравнительная политология является отраслью, которая (а) адресуется к общественно значимым вопросам политического порядка, политических режимов, социальных сил, демократических и государственных институтов, экономических процессов и наднациональных тенденций во всех регионах мира; (б) больше ориентирована на эмпирический анализ, чем на общую теорию; (в) нацелена на получение описательного и причинного знания с относительно равным балансом между ними; (г) не предназначена для прямого применения знания в публичной политике; (д) генерирует теорию в основном через индукцию; (е) полагается в основном на качественные методы эмпирического исследования» [9, р. 25]. Эту же тенденцию отмечает и Джеймс Махони: «Тогда как ранее качественная методология рассматривалась в качестве дополнительного набора «остаточных» техник, которые должны были использоваться, только если другие методы (т. е. статистические методы) были неподходящими, то сегодня подчеркивается явное преимущество качественного исследования. Этот новый акцент соответствует исследовательской практике. Компаративисты часто склоняются к качественным методам вместо или в комбинации с альтернативными техниками, так как они полагают, что качественные методы значимы для ответа на многие существенные вопросы отрасли» [10, p. 122]. Качественные методы обычно применяются при исследовании ограниченного количества стран или даже одной страны. Однако «случай» необязательно является страной, но и отдельное явление или событие может рассматриваться в качестве такового. Ряд исследователей подчеркивает, что в центре качественной методологии анализа лежит отдельный случай, что, естественно, противопоставляется серийному статистическому исследованию.

Данная дискуссия о качественных методах характерна для третьего поколения их разработчиков [11, p. 113-114]. Отличие этой дискуссии от предыдущих авторы связывают с инновационной постановкой ряда вопросов и утверждением значимости качественных методов: (1) разработка новых подходов: контрфактуальный анализ, отбор противоположных случаев, метод повторного отбора усовершенствованных понятий; (2) выявление соотношений со статистическими и формальными методами и разработка мультиметодологического подхода; (3) профессионализация в области использования качественных методов; (4) институциональное развитие сообщества исследователей, ориентирующихся на качественные методы. 
Обоснование значимости качественной методологии исследования отдельного случая вновь стало связываться с проблемой соотношения онтологии и методологии. Обоснование единства методологии и онтологии наблюдается, когда качественные методы, а с ними и исследование случаев становятся магистральным направлением в политической науке. Хотя существует дискуссия о неправомерности сопоставления различных онтологий и методологий, тем не менее выход на первый план исследования отдельного случая актуализирует другое понимание политической реальности, чем то, которое было явно положено в основание количественных и формальных методов политического исследования в начале движения за новую политологию, а потом эксплицитно признавалось всеми учеными, практикующими эти методы.

Сразу отметим, что изменение онтологической составляющей политической науки под влиянием кризиса сциентизма и поиска новых оснований политического исследования является процессом неоднозначным и не совсем явно выраженным. Можно отметить лишь тенденцию к этому, чем обоснованный и уже работающий парадигмальный сдвиг. Дискуссия часто идет в плоскости обоснования исследования отдельного случая с применением качественных методов как важного средства получения теоретических обобщений, которые бы не отличались по точности и обоснованности от традиционной политической науки. Многие полагают, что противопоставление количественных и качественных методов является надуманным; идет поиск интегративных методологических отношений. Рассматривается вопрос о характере и широте пространства теоретических обобщений, полученных с помощью качественных методов. Во многих случаях подобные методологические споры все же порождают потребность уйти от методологии в онтологию, так как нельзя не учитывать инновационный характер ведущихся дискуссий, определяемых в самой своей основе проблемой соотношения политической науки и политической реальности. Дэвид Коллиер выразил эту мысль, подчеркивая взаимосвязь методологических и субстантивных проблем для политического исследования: «Методологическая работа, отъединенная от субстантивных проблем, может утратить новизну. Методологи должны стоять ближе к сферам, где они надеются получить интересные вопросы. Соединение методологических и субстантивных проблем также мотивирует других исследователей обратить внимание на методологию» [12, p. 585]. На наш взгляд, требование соединения методологии с онтологией не случайно вывело исследователей политики на значимость качественных методов и изучение отдельных случаев. В самой методологии просвечивается явная трансформация взглядов на политическую онтологию.

\section{Первый онтологический поворот: политика как множественное и конфликтное событие}

Онтологические перспективы «поворота» были вначале вдохновлены онтологией радикальной случайности политического события Бадью, «риторической» онтологией социального антагонизма Лакло, онтологией био-власти Хардта и Негри, онтологией голой жизни Агамбена, антиметафизической онтологией реального Лакана, онтологией различий Делеза или хонтологическим подходом к политическому Деррида. Онтологический поворот, во-первых, символизировал «постфундаменталистскую» ориентацию в политической философии и теории, которая была направлена против метафизических обоснований политики и брала за основу размышления 
о политике ее «природу» как случайного, открытого, изменяющегося, проявляющегося, множественного и спорного события. В этом отношении на первый план вышла проблема политического (the political) [13], которая при всех разнообразных ее трактовках вновь настраивала философские размышления на раскрытие тела политики в ее реальном облачении и свойствах, а не в философско-реконструируемых спекуляциях.

Во второй половине 1990-х - начале 2000-х гг. была опубликована серия работ континентальных европейских философов под общим названием «Размышления о политическом». Представляя эту серию, научные редакторы указывали, что ее «цель состоит не в том, чтобы растворить специфику «философского» в «политическом» и не уклониться от вызова, который «политическое» ставит перед «философским»; скорее, каждый том серии попытается показать, что только в отношениях между ними могут быть задействованы новые возможности мысли и политики» [14], (counter-title). Важным аспектом также выступала критика захвата политической теории и философии рациональными экономическими и моральными суждениями, которые скрывали суть политики и политической мысли. Например, Уильям Кимлика в своей книге «Современная политическая философия. Введение» прямо писал о том, что хотя политическая философия отличается от моральной, однако существует фундаментальная связь между ними $[15$, р. 5]. Именно эту фундаментальную связь и пытались разрушить философы онтологического поворота. Концепции разнообразия, различия, спора, конфликта, полемики и конфронтации противостояли либеральному пониманию согласия, договора, взаимности. Именно с критикой либерализма была связана эта новая онтологическая перспектива в политическом мышлении. Шантал Муфф называла господствующую тенденцию в описании политики пост-политической и подчеркивала, что «в противоположность тому, во что пост-политические теоретики хотят нас уверить, мы являемся свидетелями не исчезновения политического в его состязательном измерении, а наоборот. Происходящее политическое сегодня разыгрывается вне морального регистра. Другими словами, оно все еще осуществляется в противостоянии мы/они, но вместо того, чтобы мы/они определялись в политических категориях, это получает моральную терминологию. Вместо борьбы между 'левыми и правыми' мы сталкиваемся с борьбой между 'правильным и ошибочным'» [16, p. 5].

Вторая тема, которая возникала в этих онтологиях, касалась возможности перевода фундаментальной онтологии в сферу политики. Возможна ли связь между философской критикой и политической практикой? Ликвидирует ли политическая онтология разрыв между мыслью и практикой, философией и политикой? В этой связи возникает широкое движение за онтологический тип мышления в политике, которое бы выполняло задачи скорее ориентационно-политические, чем просто созерцательно-объяснительные или процедурно-институциональные. Конечно, прямой вывод политики из политической онтологии был проблематичен, однако данный тип мышления предполагал подозрение как к предварительному наблюдению и схематическому теоретизированию на основе избранного методологического подхода, так и к долженствованию, проистекающему из метафизического нормативизма. Более того, сама философия становится подверженной политике, когда мысль и мышление выступают в форме политического проекта и политического предприятия. Как писал Ален Бадью, «я научился философски исследовать политику, лишь обуславливая философию политикой. Тем самым речь идет о том, что я здесь называю метаполитикой, т. е. о том, что в философии несет на себе след некоего политического условия, не являющегося ни объектом, ни тем, о чем следовало бы мыслить, но как 
раз современностью, вызывающей некоторые философские воздействия» [17, с. 143]. В этом отношении такая политическая философия, вдохновленная политикой, становится действующим фактором политической реальности.

\section{Второй онтологический поворот: новый политический реализм}

Более радикальной выступила вторая волна онтологизации политического мышления, которая ушла от рассмотрения проблематичности связи теории и реальной политики, а прямо декларировала новую политику, определяемую философией нового реализма. Новая политика определялась тем, что в производство реальности как преимущественной цели политики включались все факторы человеческой и нечеловеческой природы, включая науку, технологию, человека и вещи. В этом отношении Бруно Латур в работе «Политика природы. Как привить наукам демократию» писал, что «мы никогда не поймем значение слов ойкос, логос, фюзис и полис, если не будем рассматривать все четыре концепта одновременно» $[18$, с. 9]. Эта новая волна представлена акторно-сетевой теорией Латура, объектно-ориентированной онтологией Хармана и Мортона, плоской онтологией Деланда, спекулятивным реализмом Мейясу и витальным материализмом Беннетт.

На чем строится единство онтологического поворота? Можно выделить следующие общие идеи, перечень которых можно, конечно же, расширить:

- опасность антропоцена (отказ от центрированности на субъекте-человеке);

- против метафизики и трансцендентализма (реализм, но «странный»: любая вещь больше, чем ее проявления);

- ограниченность здравого смысла (спекулятивность, чистая сила ума, способность мыслить);

- против иерархий и властных распределений в познании вещей (плоская онтология);

- несогласие с эпистемологией (истина) и эссенциализмом (сущность и идеи), провозглашение значимости онтологий вещей/объектов (конкретность бытия объектов и его проявлений);

- против пассивности, неизменности природных объектов (пульсирующая материя, расширение понятия жизни).

Общим смыслом этого радикального поворота в политическом мышлении выступает ряд общих установок, закладывающих новые направления познания политической реальности.

Новая онтология предлагает объединить понимание реальности, отказавшись от дихотомий природа/общество, человек/животное, свобода/необходимость, индивидуальное/общее, микро/макро и т. д. Выступая против редукционизма, с одной стороны, и тотальности, с другой, этот подход ориентируется на эмерджентность и открытость целого, а также опирается на понимание «нередуцируемой социальной сложности, характерной для современного мира» [19, с. 11]; курсив мой - Л. С.). Эмерджентность здесь обозначает принцип понимания возникающего целого, несводимого к составляющим его частям; открытость целого говорит о том, что участвующие в его формировании элементы не пропадают, а занимают свое место в новом множестве; нередуцируемая социальная сложность свидетельствует о несводимости множественной целостности к каким-либо ее элементарным частицам. В этом смысле новый онтологический реализм выступает против прежнего онто-теологического способа мышления, метафизически нацеленного на сведение существующего к его предельной основе. Понять реальность как плюриверс, а не универс, когда различие 
онтологий приводит к их конфликту, является важным теоретическим следствием объектно-ориентированной онтологии.

В новом проекте возникает двойственная (и взаимосвязанная) задача политизировать онтологию и онтологизировать политику. Включить в онтологию существующего объекты (вещи) вне корреляции с человеком, не в качестве подручных, а в качестве действующих и производящих реальность означает придать их онтологии политическое значение и роль, а также расширить онтологическое содержание политики, уйдя от ее ограничения «волюнтаризмом свободно конституирующего человеческого субъекта». Критикуя за последнее ограничение политики у Рэя Брассье, Грэм Харман писал: «Но политика - это не только человеческие субъекты, это и бесчисленные неодушевленные объекты, действующие как стабилизаторы человеческого общества» [20, с. 155]. Следовательно, политизировать онтологию означает определить, какие объекты приобретают власть и влияние в процессе взаимодействий формирующейся реальности, какие объекты проявляют политический эффект в ее конструировании. Более того, взаимодействие различных онтологических объектов порождает конфликт онтологий, а соответственно, ведет к необходимости разрешать конфликтные отношения в политике. Политизировать онтологию означает, таким образом, включить ее в процессы оспаривания и производства решения. Онтологизировать политику - это признать, что политика имеет свою онтологию, несводимую к морали, экономике, рационализму, эстетике, воле, что все объекты в политике раскрывают свою политическую субстанцию, что необходимо научить жить людей во взаимодействии с объектами.

Новый реализм объектов, критически относясь к гносеологии и эпистемологии, разрабатывает такой тип онтологического анализа, который мог бы лучше учитывать особенности политической реальности. Полагая, что господство эпистемологии в философии обрекает ее на полностью антропоцентрическую референцию [21, с. 19], его представители предпринимают усилия для преодоления этого отнесения к человеку в процессе познания и создания способов описания объектной онтологической картины реальности. Эту сложную задачу они пытаются решать, используя скорее язык технологий, а не сущностей. Понятия ассамбляжи, сборки, стыковки, переводы, картографии, маркировки и др. используются для описания объектов и их взаимных связей. В политической науке такая технологическая терминология используется для анализа особых объектов и состояний. Так, с помощью акторно-сетевой теории исследуется движение французских фермеров на основе критики онтологических предположений нынешних законов о семенах [22]; изучаются возможности политики онтологии для разрушения колониальной системы, культивирования плюриверса и создания науки о деколонизации [23]; утверждается, что политические экологические конфликты в различной степени связаны не с использованием природных ресурсов, а с конфликтами из-за онтологий между ныне живущими коренными жителями и современным капиталом, государством и наукой [24, p. 551]; объектно-ориентированный подход используется в географическом изучении власти и политики, когда объекты рассматриваются в качестве феноменологических вирусов, охраняющих мир [25]. В большей мере новый реализм используется скорее как стратегия, чем выверенная методическая ориентация. Вместе с тем данная ориентация порождает некоторые проблемы. Микко Йоронен и Йоки Хэкли, например, указывают на две из них, которые возникают при изучении политики, когда нет разделения на человеческий субъект и нечеловеческие объекты и когда все имеет политический потенциал. Первая проблема имеет дело с идеей ответственности (она 
становится относительной), вторая проблема связана с представлением о политическом вообще (оно исчезает, когда все политизируется) [26, р. 569-570].

Политическая реальность с позиции новой онтологической политики разворачивается перед нашими глазами и требует деятельного участия сейчас, без упования на прошлые события и без особого расчета на будущее. Объекты, вещи, люди, силы, идеи проявляют свою потенциальную политическую субстанцию в актуальной борьбе и конфликте сетевых взаимоотношений. Поэтому принципом выступает акцент на актуальности существующего, а не на потенциальности возможного. Анализируя стрелы времени модерна, Бруно Латур показывает отношение новых онтологов к истории, современности и проектам будущего. Политическая экология, пишет он, - «должна изменить механизм, который генерирует различие между прошлым и будущим, остановить маятник, который задает ритм темпоральности людей модерна» [27, с. 209]. Этот позитивизм и прагматику настоящего Латур особо подчеркивает в своем уточнении вопроса о том, что такое политика и политическое. Политика, по его мнению, которое он обосновывает, обращаясь к Дьюи, Липпману, Рорти и Патнэм, всегда связана с постановкой и решением насущных проблем, волнующих публику, вопросов, вызывающих озабоченность, ситуаций, требующих решения. В этом отношении политика есть обращение к сегодняшним делам и заботам, тем более что по ним нет согласия. При прохождении различных стадий политического (появление проблемы, ее превращение в публичную, принятие этой проблемы суверенными властями в качестве общественного блага и предмета воли, подключение публики к ее решению, переход проблем в обычную стадию управленческой рутины), «таким образом, прогрессивная композиция общего мира будет определяться двумя основными элементами: какие вещи должны интересовать политику и как она должна поворачиваться вокруг этих вещей» [Там же. Р. 819].

Необходимо принять принципиальный индетерминизм онтологической реальности, контингентность происходящего, неопределенность и открытость его к трансформациям. Не все представители этого направления критически относятся к причинности. Если она и признается, то не в вещах/объектах, а в их проявлениях/связях. Некоторые считают, что нужно отказаться от линейной причинности и рассматривать ее в качестве продуктивного фактора, когда одно событие порождает другое событие, а не обусловливает его $[19$, с. 20]. На место причинной зависимости иногда ставятся корреляционные связи (Латур) ${ }^{1}$. Но в основном новый онтологический взгляд на реальность предпочитает контингентность, т. е. принцип, в соответствии с которым «может произойти все, что угодно - даже то, что ничего не произойдет, и все останется как есть» $[28$, с. 89]. Квентин Мейясу является наиболее последовательным защитником и разработчиком контингентности на основе критики корреляционизма (корреляция бытия и мышления), принципов достаточного основания (все существующее имеет свою причину) и конца рациональной метафизики (деабсолютизация, приведшая к фидеизму). Знание существующей хаотической реальности, следовательно, возможно с использованием принципов неоснования и непротиворечивости: «под этим понимается, что непротиворечие не означает какую-нибудь фиксированную эссенциальность,

\footnotetext{
${ }^{1}$ В качестве примера приведем исследование Д. Чандлера, который описывает современное цифровое управление как управление следствиями, а не причинными связями, фокусируясь на работах Ульриха Бека и Бруно Латура по установлению проблемы обусловленного обстоятельствами взаимодействия, а не причинной глубины, как ключа к возникающим последствиям, которые могут быть неожиданными и катастрофическими $[29$, p. 23-24].
} 
а имеет в качестве онтологического смысла необходимость контингентности, иначе говоря, необходимость всемогущего Хаоса» [Там же. С. 102].

Критика этой волны онтологического мышления обращает внимание на чрезмерную политизацию онтологии и постгуманизм как идею рассматривать политику бессубъектно, выявляются недостатки спекулятивного подхода к рассмотрению политики, который некоторыми исследователями рассматривается в качестве современной формы софистики. Вместе с тем идет процесс освоения новой онтологии в ходе исследования цифровизации, искусственного интеллекта, экологии, постколониализма, публичного управления. В противопоставлении постгуманизму формируется трансгуманизм как политика принятия объектов в человеческий мир.

В определенном отношении все вышеперечисленные тенденции и повороты в политическом познании идут параллельно. Начало нынешнего столетия зафиксировало открытость политической науки к поиску новых подходов и интерпретаций политики. Онтологический и методологический кризис политической науки наложился на кризис демократии, политической репрезентации, рационального выбора. Постправда и популизм внесли свои дополнительные краски в неопределенность описания политической реальности, а использование сетевых медиа выявило возможность усиления контроля за политическими суждениями, их догматизацию и направленную мобилизацию. Новые краски в кризис добавили цифровые технологии, которые поставили под сомнение традиционные формы политики и публичного управления и обострили процесс политического познания. Вопрос о том, в каком направлении будет развиваться поиск обновленной политической науки, как и политики в целом, остается открытым. Ясно, что многообразие подходов и установок необходимо взять в расчет, без чего решение проблемы вряд ли возможно.

\section{Ссылки / References}

1. Гаман-Голутвина О. В. Преодолевая методологические различия: споры о познании политики в эпоху неопределенности // Политические исследования. Полис. 2019. № 5. С. $19-42$.

2. Jervis R. System Effects: Complexity in Political and Social Life. Princeton: Princeton University Press, 1997. 328 p.

3. Political Complexity: Nonlinear Models of Politics / Ed. by D. Richards. Ann Arbor: University of Michigan Press, 2003. 349 p.

4. Complexity and Policy Analysis: Tools and Methods for Desining Robust Policies in a Complex World / Ed. by L. Dennard, K. Richardson, G. Morcol. Marblehead, MA: ISCE Publishing, 2008. $428 \mathrm{p}$.

5. Geyer R. Complexity and Public Policy: A New Approach to 21st Century Politics, Policy and Society. L., N.Y.: Routledge, 2010. 224 p.

6. Elliot E. Complexity, Politics, and Public Policy // Knowledge Management, Organizational Intelligence and Learning and Complexity / Ed. by L. D. Kiel. Oxford: EOLSS Publishers, 2003. P. 3-42.

7. Сморгунов Л. В. Сложность в политике: некоторые методологические направления исследований // Вестник С.-Петерб. ун-та. Серия 6. 2012. Вып. 4. С. 90-101.

8. Munck G. The Past and Present of Comparative Politics // Munck G., Snyder R. (eds.). Passion, Craft, and Method in Comparative Politics. Baltimore, MD: The Johns Hopkins University Press, 2007. P. 32-62. 
9. Munck G., Snyder R. Debating the Direction of Comparative Politics // Comparative Political Studies. 2007. Vol. 40. № 1. P. 5-31.

10. Mahoney J. Qualitative Methodology and Comparative Politics // Comparative Political Studies. 2007. Vol. 40. № 2. P. 122-144.

11. Bennett A., Elman C. Qualitative Methods. The View From the Subfields // Comparative Political Studies. 2007. Vol. 40. № 2. P. 111-121.

12. Collier D. Critical Junctures, Concepts, and Methods // Passion, Craft, and Method in Comparative Politics / Ed. by G. Munck, R. Snyder. Baltomore: The Johns Hopkins University Press, 2007. P. 556-600.

13. Rosenthal I. Ontology and political theory: A critical encounter between Rawls and Foucault // European Journal of Political Theory. 2019. Vol. 18. № 2. P. 238-258.

14. Williams J. Lyotard \& the Political. L., N.Y.: Routledge, 2000. 153 p.

15. Kymlicka W. Contemporary Political Philosophy. An Introduction. 2nd ed. Oxford, N.Y.: Oxford University Press, 2002. 497 p.

16. Mouffe Ch. On the Political (Thinking in Action). L., N.Y.: Routledge, 2005. 144 p.

17. Бадью А. Мета/Политика: Можно ли мыслить политику? Краткий трактат по метаполитике / Пер. с фр. Б. Скуратов, К. Голубович. М.: Логос, 2005. 240 с.

18. Латур Б. Политика природы. Как привить наукам демократию. М.: Ад Маргинем Пресс, 2018. 336 c.

19. Деланда М. Новая философия общества. Теория ассамбляжей и социальная сложность. Пер. с англ. К. С. Майоровой. Пермь: Гиле Пресс, 2018. 170 с.

20. Х Харман Г. Спекулятивный реализм: введение. М.: РИПОЛ классик, 2019. 496 с.

21. Брайант Л. Демократия объектов / Пер. с англ. О. С. Мышкина. Пермь: Гиле Пресс, 2019. 320 c.

22. Demeulenaere E. A Political Ontology of Seeds: The transformative Frictions of a farmers' movement in Europe // Focaal - Journal of Global and Historical Anthropology. 2014. № 69. P. 45-61.

23. Blaney D. L., Tickner A. B. Worlding, Ontological Politics and the Possibility of a Decolonial IR // Millennium: Journal of International Studies. 2017. Vol. 45. № 3. P. 293-331.

24. Bormpoudakis D. Three implications of political ontology for the political ecology of conservation // Journal of Political Ecology. 2019. Vol. 26. № 1. P. 545-566.

25. Shaw I., Meehan K. Force-full: Power, Politics Object-oriented Philosophy // Area. 2013. Vol. 45. № 2. P. 216-222.

26. Juronen M., Häkli J. Politicizing ontology // Progress in Human Geography. 2017. Vol. 41. № 5. P. 561-579.

27. Latour B. Turning around Politics: A Note on Gerard de Vries' Paper // Social Studies of Science. 2007. Vol. 37. № 5. P. 811-820.

28. Мейясу К. После конечности. Эссе о необходимости контингентности. Екатеринбург, М.: Кабинетный ученый, 2015. 196 с.

29. Chandler D. Digital Governance in the Anthropocene: The Rise of the Correlational Machine // Chandler D., Fuchs C. (eds.) Digital Objects, Digital Subjects: Interdisciplinary Perspectives on Capitalism, Labour and Politics in the Age of Big Data. London: University of Westminster Press, 2019. P. 23-42. 